\title{
Q R
}

Quellada. Topical treatment for scabies and lice: see GAMMA-BENZENE HEXACHLORIDE.

Questran. For hypercholesterolaemia: See CHOLESTYRAMINE.

Quinaband. Impregnated bandage: see CALAMINE, CLIOQUINOL, ZINC OXIDE.

Quinocort. Anti-infective/corticosteroid cream for topical treatment of infected eczema and similar skin conditions: See HYDROCORTISONE, HYDROXYQUINOLINE.

Quinoderm. Topical treatment for acne: See BENZOYL PEROXIDE, HYDROXYQUINOLINE.

\section{Quinoderm with 1 percent} hydrocortisone. As Quinoderm plus HYDROCORTISONE.

Quinoped. Topical antifungal for feet: See BENZOYL PEROXIDE, HYDROXYQUINOLINE.

Rabro (d). Antacid: see CALCIUM CARBONATE, FRANGULA, LIQUORICE, MAGNESIUM OXIDE.

Rapifen (c). Narcotic analgesic: see ALFENTANIL.

Rapitard. Long-acting mixture of purified beef and pork insulins: see INSULIN.

Rastinon. Hypoglycaemic: see TOLBUTAMIDE.

Razoxin. Antitumour: see RAZOXANE.
RBC. Topical antihistamine: see ANTAZOLINE, CALAMINE, CAMPHOR, CETRIMIDE.

Recormon. Hormone treatment for anaemia in chronic renal failure in patients on chronic dialysis: see EPOETIN BETA.

Redeptin. Depot injection tranquillizers/anti-psychotic: see FLUSPIRILENE.

Refolinon. Antagonizes antifolate cytotoxic drugs: see FOLINIC ACID.

Regaine. Topical treatment for malepattern baldness: see MINOXIDIL.

Regulan. Purgative: see ISPAGHULA.

Rehibin. For anovulatory infertility: see CYCLOFENIL.

Rehidrat. Electrolytes and sugars supplied in a powder for reconstitution into solution. Used orally to correct fluid and electrolyte imbalance (e.g., due to diarrhoea and vomiting).

Relaxit. Enema for constipation: see GLYCEROL, SODIUM CITRATE, SODIUM LAURYL SULPHATE, SORBIC ACID, SORBITOL.

Relefact LH-RH. For diagnostic use in delayed sexual development and failure of pituitary gland function: see GONADORELIN.

Relifex. Non-steroid anti-inflammatory analgesic: see NABUMETONE. 